\title{
Anti-bacterial antibody and T cell responses in bronchiectasis are differentially associated with lung colonization and disease
}

Fathia G. Jaat ${ }^{1,5}$, Sajidah F. Hasan ${ }^{1,6}$, Audrey Perry ${ }^{2}$, Sharon Cookson ${ }^{1}$, Santosh Murali ${ }^{1}$, John D. Perry ${ }^{1,2}$, Clare V. Lanyon ${ }^{1}$, Anthony De Soyza ${ }^{3,4+}$ and Stephen M. Todryk ${ }^{1,4^{*}+}$ (D)

\begin{abstract}
Background: As a way to determine markers of infection or disease informing disease management, and to reveal disease-associated immune mechanisms, this study sought to measure antibody and T cell responses against key lung pathogens and to relate these to patients' microbial colonization status, exacerbation history and lung function, in Bronchiectasis (BR) and Chronic Obstructive Pulmonary Disease (COPD).

Methods: One hundred nineteen patients with stable BR, 58 with COPD and 28 healthy volunteers were recruited and spirometry was performed. Bacterial lysates were used to measure specific antibody responses by ELISA and T cells by ELIspot. Cytokine secretion by lysate-stimulated T cells was measured by multiplex cytokine assay whilst activation phenotype was measured by flow cytometry.

Results: Typical colonization profiles were observed in BR and COPD, dominated by P.aeruginosa, H.influenzae, S. pneumoniae and M.catarrhalis. Colonization frequency was greater in BR, showing association with increased antibody responses against P.aeruginosa compared to COPD and HV, and with sensitivity of $73 \%$ and specificity of 95\%. Interferon-gamma T cell responses against P.aeruginosa and S.pneumoniae were reduced in BR and COPD, whilst reactive T cells in BR had similar markers of homing and senescence compared to healthy volunteers. Exacerbation frequency in BR was associated with increased antibodies against $P$. aeruginosa, M.catarrhalis and S. maltophilia. T cell responses against H.influenzae showed positive correlation with $\mathrm{FEV}_{1} \%(r=0.201, p=0.033)$ and negative correlation with Bronchiectasis Severity Index $(r=-0.287, p=0.0035)$.

Conclusion: Our findings suggest a difference in antibody and T cell immunity in BR, with antibody being a marker of exposure and disease in BR for P.aeruginosa, M.catarrhalis and H.influenzae, and T cells a marker of reduced disease for H.influenzae.
\end{abstract}

Keywords: Bronchiectasis, Antibodies, T cells, Lung function, Exacerbation, COPD

\footnotetext{
* Correspondence: stephen.todryk@northumbria.ac.uk

${ }^{+}$Anthony De Soyza and Stephen M. Todryk contributed equally to this work.

${ }^{1}$ Faculty of Health \& Life Sciences, Northumbria University, Newcastle upon

Tyne NE1 8ST, UK

${ }^{4}$ Institute of Cellular Medicine, Newcastle University, Newcastle upon Tyne

NE2 $4 \mathrm{HH}$, UK

Full list of author information is available at the end of the article
}

(c) The Author(s). 2018 Open Access This article is distributed under the terms of the Creative Commons Attribution 4.0 International License (http://creativecommons.org/licenses/by/4.0/), which permits unrestricted use, distribution, and reproduction in any medium, provided you give appropriate credit to the original author(s) and the source, provide a link to the Creative Commons license, and indicate if changes were made. The Creative Commons Public Domain Dedication waiver (http://creativecommons.org/publicdomain/zero/1.0/) applies to the data made available in this article, unless otherwise stated. 


\section{Background}

The chronic lung diseases of bronchiectasis (BR) and chronic obstructive pulmonary disease (COPD) are both associated with recurrent airway infections. COPD is a major cause of death globally, with numbers of deaths rising [1], and BR is underestimated with incidence rising in the UK by around 6\% annually [2]. Whilst they differ in disease causation, established disease in both is mainly characterised by repeated or persistent heavy bacterial colonization of the damaged lower respiratory tract. Such infection is associated with inflammation, mucus production, and reduced ciliary action, which promotes further infection, inflammation and tissue damage, in a vicious cycle [3]. Studies have suggested that infection causes disease exacerbation and diminished lung function, which are often proportional to the bacterial load and to reduced diversity $[4,5]$. More recent findings propose more species-rich lung ecologies where alterations in specific bacterial populations, dysbiosis, is at the heart of clinical disease [6, 7]. Pathogenic bacteria, as determined clinically by microbiological culture of expectorated sputum, are dominated by organisms specific to these diseases including Pseudomonas aeruginosa, Haemophilus influenzae, Streptococcus pneumoniae and Moraxella catarrhalis [8]. Recent studies using DNA-sequencing technology reveal more detailed bacterial ecosystems in the lungs of diseased patients, but with culture approaches mainly corroborated $[9,10]$. P.aeruginosa is considered the major cause of morbidity (increased exacerbations and reduced lung function) and mortality in BR [11], particularly during chronic infection and mucoid characteristics of the bacterium [12], which may allow evasion of host immunity. Non-typeable strains of Haemophilus influenzae (NTHi) are frequently found in BR [13] and are not targeted by current vaccines. Both pathogens are also common in COPD albeit with a reduced frequency of Pseudomonas infections as compared to BR [14]. Furthermore, less frequent suppurative infection and sputum production in COPD results in lower detection of pathogenic microbes, implying fewer infections than BR. Failure to produce sputum for microbiology, particularly in younger BR patients and in many COPD patients, as well as intermittent negative cultures, means that immune biomarkers of disease may provide a useful adjunct for directing clinical management.

Knowledge of immunity in BR is limited, but studies suggest immune system genes that are involved in presentation of antigens to $\mathrm{CD}_{4}^{+} \mathrm{T}$ cells, such as HLA-DR1 and DQ5, play a role $[15,16]$. Notably, a role for adaptive immune responses (specific antibodies and $\mathrm{T}$ cells) in protection against P.aeruginosa and H.influenzae, has been demonstrated in human vaccine trials in cystic fibrosis-related bronchiectasis $[17,18]$ and in mouse vaccination models $[19,20]$. Furthermore, the above-mentioned lung pathogens appear in individuals with defined immunodeficiencies [21], underlining the role of antibodies and phagocytes in protection. Whilst healthy individuals are exposed to the same pathogenic organisms as diseased individuals, healthy lungs typically have low levels of bacterial species, reflecting the naso-pharynx [22]. Immune responses against pathogenic microbes do not cause overt immunopathology in healthy individuals, but may contribute to disease in colonized patients due to continuous immune stimulation by the localised high antigen doses, particularly through excessive Th17 responses that promote neutrophil infiltration [23]. Together with inflammatory cytokines, neutrophils are abundant in the sputum of BR patients, and decline after antibiotic treatment [24]. It is possible that dysfunction of both innate and adaptive immunity contribute directly or indirectly to disease in both BR and COPD. The aim of this study was to characterise antibody and $\mathrm{T}$ cell responses against key lung microbes in disease-stable patients with BR and COPD, characterised by the Bronchiectasis Severity Index (BSI) and GOLD guidelines, respectively, in comparison to controls (healthy volunteers), and to relate the immune responses to culture-based bacterial colonization, lung function and frequency of exacerbation.

\section{Methods}

\section{Study participants and samples}

Ethical approval for the project was granted by the local NHS Research Ethics Committee, the NRES Committee North East - County Durham \& Tees Valley (ref 12/NE/ 0248). Adult patients with (non-CF) BR, COPD and healthy volunteer (HV) controls, were recruited at the Freeman Hospital, Newcastle upon Tyne. Female to male ration was about $1.5: 1$. BR is routinely confirmed by high-resolution computed tomography (HCRT), and COPD according to prevailing GOLD guidelines (BTS and NICE 2010, [25]). Diverse aetiologies of BR were included in the study, with the exception of known immunodeficiency.

Patients were clinically stable at the time of assessment. They underwent spirometry to determine forced expiratory volume in $1 \mathrm{~s}\left(\mathrm{FEV}_{1}\right)$, and Forced Vital Capacity (FVC), from which FEV1\% predicted, FEV1/ FVC ratio and FVC \% predicted were obtained. The bronchiectasis severity index (BSI) score, as previously validated [26], was assessed. Patients were divided into 2 groups: either those with one severe exacerbation requiring hospitalisation or those with 3 or more exacerbations per year, compared to those not requiring hospitalisation and having less than 3 exacerbations per year. The exacerbations were determined for the preceding 12 months. Colonization history of patients was also available going back at least 4 years. Patients were categorised by pathogen status based on positive sputum cultures. 'Chronic 
colonization' was defined here as 2 positive sputum cultures at least 3 months apart in 12 months. 'Chronic currently' was defined as a positive sputum culture at time of blood sampling (for immune responses), and more than 2 positive sputum cultures in 12 months. 'Previously chronic' was defined as more than 2 positive sputum cultures in 12 months $>2$ years ago. 'Occasional' infection was $\geq 1$ positive sputum culture per year. 'No colonization' was sputum culture negative over at last 3 years (Table 3 ).

\section{Sample processing and bacterial culture}

Heparinized venous blood samples from patients and healthy controls were processed to give plasma for ELISA and peripheral blood mononuclear cells (PBMC) for $\mathrm{T}$ cell assays (detailed in Additional file 1). Sputum samples were cultured in the Microbiology Department, Freeman Hospital, according to national standards.

\section{Enzyme-linked immunosorbent assay (ELISA) for serum antibody measurement}

An indirect enzyme-linked immunosorbent assay (ELISA) method was used: to determine optimal dilutions for the coating of microbe-derived antigens, for initial serum screening, and to undertake titration for total IgG (all subclasses combined) to give an end-point titre (e.g. 1 in 1000), and for the measurement of individual Ig subclasses (given as absorbance for 1 in 25 dliution), as described previously [27](see Additional file 1).

\section{T cell responses to microbial antigens}

ELIspot as previously optimised and described [28] (see Additional file 1) was used to measure $\mathrm{T}$ cell responses against a range of stimuli including bacterial lysates plus selected peptide epitopes where available. For cell activation and surface staining of cells, PBMC were thawed and activated with stimuli for $20 \mathrm{~h}$ as detailed in the supplement. Intracellular staining was performed to determine the number and phenotype of IFN $\gamma$-producing or activated $\mathrm{CD} 9^{+} \mathrm{T}$ cells following stimulation.

\section{Measurement of cytokines in culture supernatants using multiplex ELISA}

Cytokines in supernatants from stimulated PBMCs were measured using the Mesoscale Scale Discovery (MSD) multiplex cytokine Kit (Meso Scale Diagnostic, LLC, Gaithersburg, USA). Multiplex kit - pro-inflammatory panel 1 (for IL-1 $\beta$, IL-2, IL-4, IL-6, IL-8, IL-10, IL-12p70, TNF $\alpha$ ) and cytokine panel 2 (IL-17A, IL-5) were used. See Additional file 1.

\section{Statistics}

The immunological data was tested for normal distribution using the Shapiro-Wilk test. For normally distributed data t-test and Pearson correlation was used whilst for not normally distributed data the Mann-Whitney $U$ test and Spearman's correlation was used. A priori calculations based on our previous data suggested that sufficient numbers were included to detect a modest effect with 0.9 power to a significance level of 0.05. SPSS v.15 and Graph Pad Prism were used for analysis. The cut-off value for statistical significance was $p<0.05$.

\section{Results}

\section{Clinical data}

This study examined antigen-specific immune responses in $119 \mathrm{BR}$ and $58 \mathrm{COPD}$ patients, and in $28 \mathrm{HV}$ (Table 1), against lung pathogens that are commonly isolated from these patient groups. The patient groups showed typical clinical features, similar to previously-published reports e.g. average $\mathrm{FEV}_{1} \%$ predicted, which was 68 for $\mathrm{BR}, 49$ for COPD and 113 for HV. FVC \% predicted and FEV1/FVC ratio were also reduced in the patient groups compared to $\mathrm{HV}$. The BR group was predominantly of a post-infection aetiology, whilst COPD was smoking-related, and all patients with BR and COPD were in a clinically stable state with no current exacerbation. At the time of taking the blood samples, the BR group had a higher proportion of patients producing sputum (93\%) that could be microbiologically tested than COPD (66\%), and BR patients showed greater overall populations infected with the main bacterial species (Table 2), many with multiple species. H.influenzae was the most commonly identified species in both BR and COPD, followed by P.aeruginosa, S.pneumoniae and M.catarrhalis in BR, and M.catarrhalis, S.pneumoniae and P.aeruginosa in COPD.

\section{Antibody responses}

The first experiments involved ELISA to determine antibody levels (total specific IgG), by end-point titre, against the main bacterial species in BR, COPD and HV. BR showed significantly higher levels of antibody against

Table 1 Demographics of the subjects included in this study

\begin{tabular}{llll}
\hline Characteristics & BR & COPD \\
$n=119$ & $\begin{array}{l}n=58 \\
\text { Sex (no.) }\end{array}$ & $\begin{array}{l}\text { HV } \\
n=28\end{array}$ \\
Male/female) & $45 / 74$ & Not av. & Not av. \\
Age (y) & $65 \pm 1.08$ & $69 \pm 1.23$ & $54 \pm 3.01$ \\
Exacerbations (per year) & $4 \pm 0.29$ & $3 \pm 0.38$ & Not app. \\
Smoking history (pack years) & $8 \pm 1.33$ & $47 \pm 4.08$ & Not av. \\
FEV 1 (\% predicted) & $68 \pm 2.68$ & $49 \pm 2.70$ & $113 \pm 2.83$ \\
FVC (\% predicted) & $82 \pm 2.48$ & $77 \pm 2.40$ & $118 \pm 2.7$ \\
FEV 1 /FVC ratio & $66 \pm 1.52$ & $50 \pm 2.17$ & $83 \pm 1.75$ \\
\hline Valus are presented as means \pm SEM
\end{tabular}

Values are presented as means \pm SEM, exacerbations represents the number per year. FEV ${ }_{1}$ represent forced expiratory volume in the first second and FVC, forced vital capacity. Not av., indicates the data are not available, whereas Not app., means that the category was not applicable 
Table 2 Microorganisms isolated from the sputum of patients with $\mathrm{BR}$ and $\mathrm{COPD}$

\begin{tabular}{lll}
\hline Microorganism Identified & $\begin{array}{l}\text { Bronchiectasis } \\
\text { patients (\%) }\end{array}$ & $\begin{array}{l}\text { Chronic obstructive } \\
\text { pulmonary disease } \\
\text { patients (\%) }\end{array}$ \\
\hline NT. H.influenzae & 63.8 & 31 \\
P. aeruginosa & 56.3 & 12.0 \\
S. pneumoniae & 44.5 & 17.2 \\
M. catarrhalis & 37.8 & 24.1 \\
A. fumigatus & 22.6 & 3.4 \\
S. maltophilia & 15.9 & 3.4 \\
Candida. sp & 14.4 & 6.9 \\
S aureus & 30.3 & 1.7 \\
E.coli & 20.1 & 5.2 \\
No pathogen isolated & 2.5 & 17.2 \\
No sputum produced & 6.8 & 43.7
\end{tabular}

BR patients $n=119$; COPD patients $n=58$

$N T=$ non-typeable

P.aeruginosa, H.influenzae and S.maltophilia compared to HV (Fig. 1a). COPD failed to show significant increase from HV for any of the bacteria. HV only showed significantly higher antibody responses than BR and COPD against S.pneumoniae.

The next aim was to relate specific IgG antibody levels against bacteria, to bacterial colonization status and history. Because of the relatively low infection rates in COPD, the numbers were insufficient to determine significance, and so we focussed on BR. BR patient pathogen status was analysed and condensed into a categorization shown in Table 3, indicating 'current chronic', 'previous chronic,' 'occasional', or 'no colonization'. Whilst there was an overall trend for antibody titre to increase based on colonization (Fig. 1b), this was only significant for P.aeruginosa and S.maltophilia. We further studied immunoglobulins by class and isotype across the disease groups and found in general higher levels of IgG1 and IgA in BR than COPD (Fig. 1e-g).

\section{T cell responses}

$\mathrm{T}$ cell responses, in the form of IFN $\gamma$ spot-forming cells per $10^{6} \mathrm{PBMC}$, were measured against the bacterial antigens as for the antibodies. In contrast to the antibody responses, there was an overall trend towards the BR and COPD groups having lower $\mathrm{T}$ cell responses than the HV group (Fig. 1c). BR and COPD both had significantly lower responses than $\mathrm{HV}$ against P.aeruginosa and S.pneumoniae. As with the antibody responses, the relatively low infection rates in COPD meant that there were insufficient numbers of infected patients to determine significance and so BR was focussed upon for relating to colonization (Fig. 1d). Whilst there was an overall trend for $\mathrm{T}$ cell responses against all antigens to associate with an occasional number of exposures, as opposed to none or chronic, this was not significant.

\section{Exacerbation and lung function}

The contribution of bacterial colonisation, as per Table 3, to lung function as measured by $\mathrm{FEV}_{1} \%$ predicted, was examined in the BR cohort. Overall there was a downward trend in lung function as bacterial colonisation became more frequent and with current positive cultures (Fig. 2a), with P.aeruginosa, M.catarrhalis and S.maltophilia all showing a significant reduction. The numbers with $M$.catarrhalis and S.maltophilia were low $(n=10$ and 9, respectively) with 52 and $75 \%$ of these, respectively, being co-colonised with P.aeruginosa.

Since exacerbation of disease is a key event in need of urgent clinical management, and makes up part of the validated BSI scoring, exacerbation history of the BR patients was used to determine whether there were any informative associations with immunological responses. The patients were compared based on them having less than 3 exacerbations, greater than or equal to 3 , and those that were hospitalised within the last year. This breakdown of the patients was first validated by examining the $\mathrm{FEV}_{1} \%$ predicted within the groups compared to HV (Fig. 2b). A significant decrease in lung function was seen moving from $\mathrm{HV}$, through $<3$ exacerbations, $\geq 3$ exacerbations, to hospitalised. Since the hospitalised group comprise a variable causality (and not necessarily greater disease) and was relatively small in number, this was omitted from further analysis. Small but statistically significant increases in IgG titres against P.aeruginosa, H.influenzae and M.catarrhalis were seen between < 3 and $\geq 3$ exacerbations (Fig. $3 \mathrm{a}-\mathrm{c}$ ). For $\mathrm{T}$ cell responses no significant differences were seen between the 2 groups for any bacterium (Fig. 3d-f).

\section{T cell phenotypes}

Since $\mathrm{T}$ cell responses of a single Th type (Th1/IFN $\gamma$ ) may not be the only response against the lung bacteria, antigen-specific $\mathrm{T}$ cell cytokine responses were also measured in the supernatants of antigen-stimulated PBMC by multiplex cytokine analysis (Fig. 4a-h). A sub-group of BR patients who were good responders to the antigens, determined by both IFN $\gamma$ ELIspot and by CD69 expression following antigen-stimulation, were selected for stimulation, as well as similarly good $\mathrm{HV}$ responders. For IFN $\gamma$, IL-2 and IL-17 responses the BR patients showed a trend, though not significant, towards reduced levels for both P.aeruginosa and H.influenzae compared to HV. For IL-4, BR patients showed marginally reduced responses for P.aeruginosa but significantly increased responses to H.influenzae compared to HV, although the responses showed considerable variability. Finally, IL-10 responses showed a trend for increased response in BR 

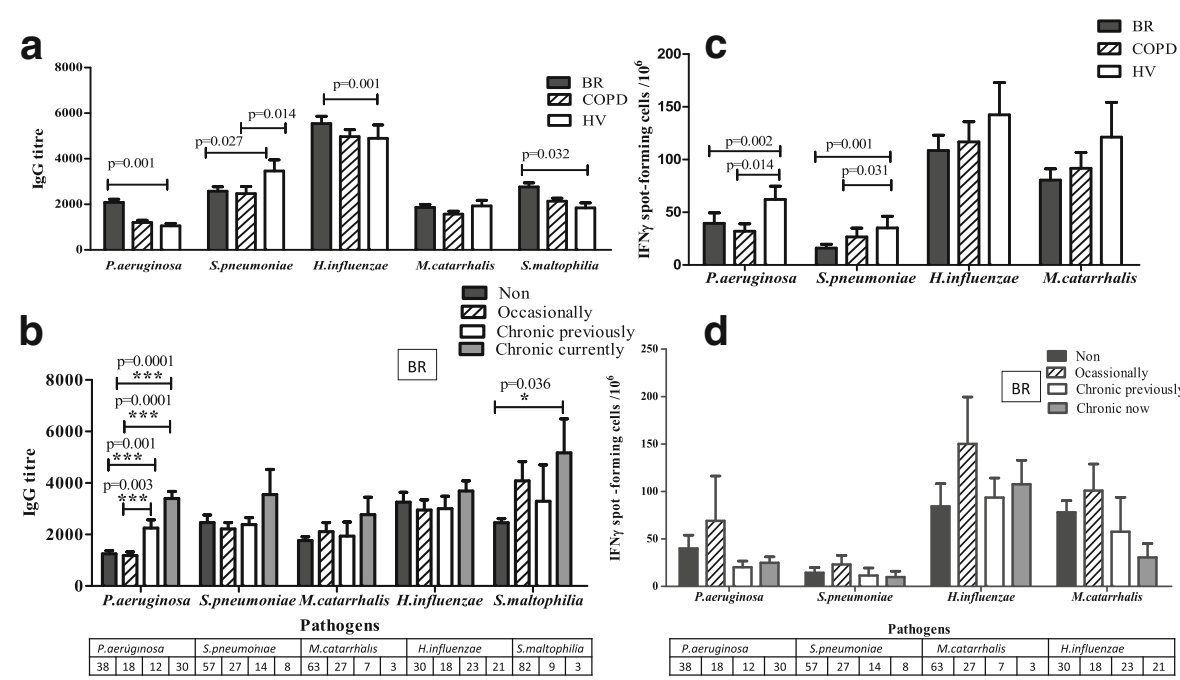

e
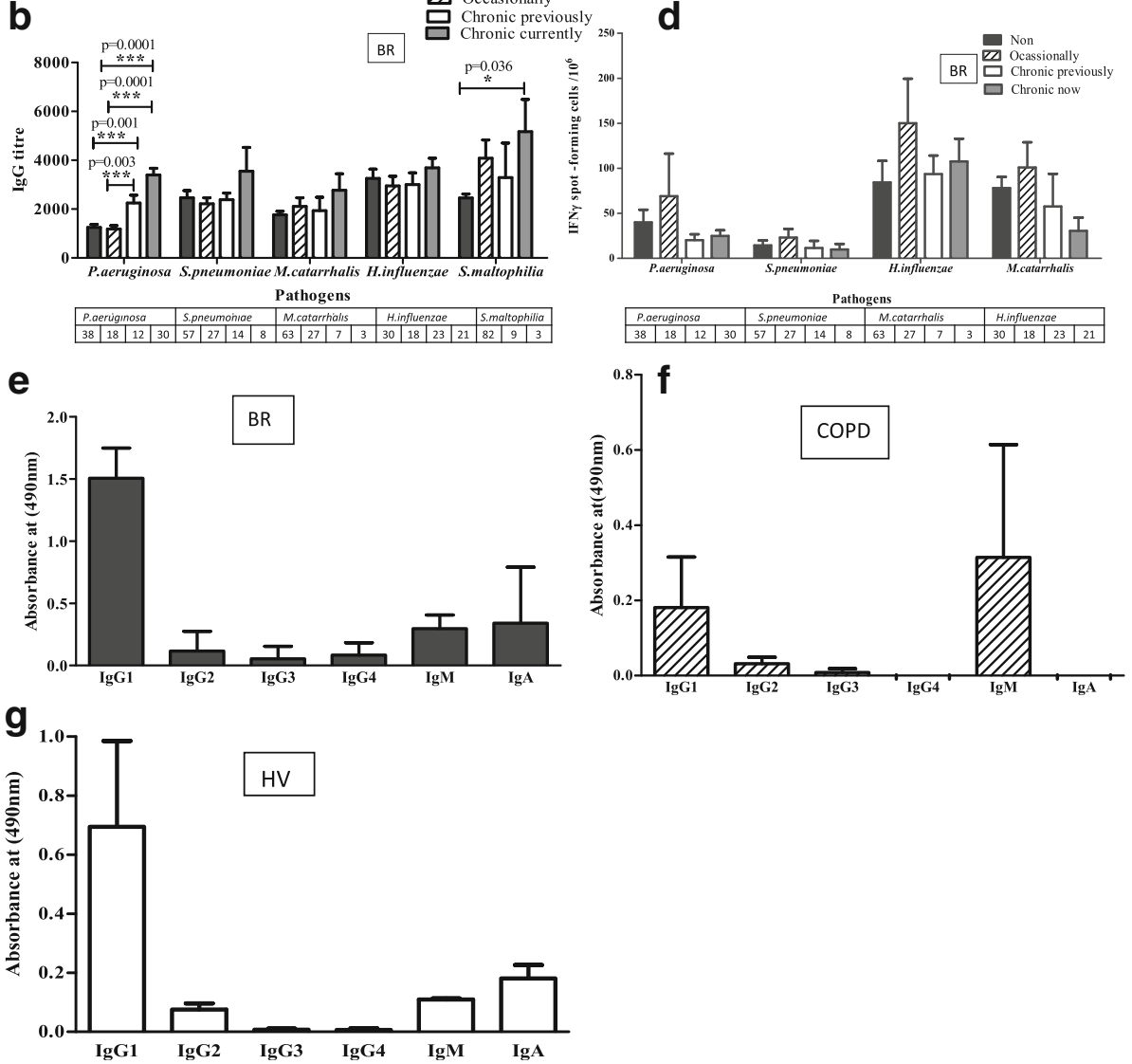

Fig. 1 Anti-bacterial antibody and T cells responses. Antibody levels against bacterial antigens were measured by ELISA: (a) IgG titres (1/value) against bacteria in BR, COPD and HV groups; (b) Antibody responses against bacteria were compared based on bacterial colonization. T cell responses against bacterial antigens were measured by IFNY ELIspot: (c) IFNY spot-forming cells per $10^{6}$ PBMC against bacteria in BR, COPD and HV groups; (d) IFNy spot-forming cells per $10^{6}$ PBMC against bacteria were compared based on bacterial colonization. Anti-pseudomonas Ig subclasses and IgG isotypes in BR (e), COPD (f) and HV (g) subgroups. Mean value + SEM are given. ${ }^{*} p<0.05,{ }^{* * *} p<0.001$. Mann-Whitney tests were performed

Table 3 Classification of patients based on sputum microbiological results

\begin{tabular}{lll}
\hline 0 & No pathogen isolated (NPI) & \\
\hline 1 & Occasional & $\geq 1$ isolation in a year \\
& & Chronic colonization is defined by the isolation of bacteria \\
& in sputum culture on 2 or more occasions, 3 months apart, within 1 year \\
3 & Chronic previously & Chronic in preceding 5 years but not last 2 years
\end{tabular}




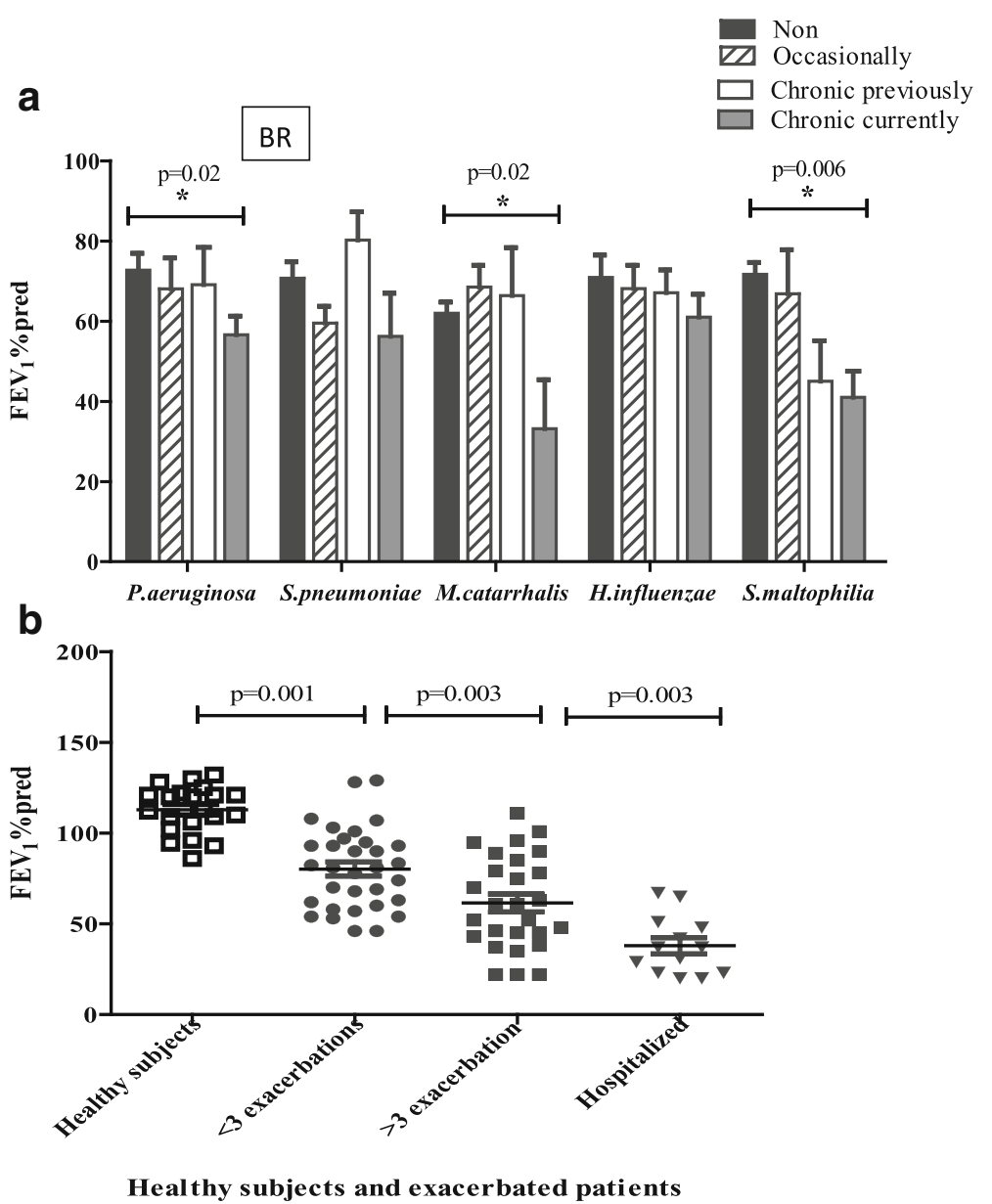

Fig. 2 Lung function and exacerbation in BR. FEV1\% predicted is a measure of lung function. (a) FEV1\% predicted in BR patients grouped based on their bacterial colonization. (b) FEV1\% predicted in BR patients based on exacerbation in the last year, and in HV - healthy subjects. Mean values + SEM are given. Mann-Whitney tests were performed

over $\mathrm{HV}$ for both antigens, but again with much variability. All other cytokine responses tested were equivocal.

Flow cytometry analysis was used to further characterise antigen-responding $\mathrm{T}$ cells in the same subgroups of $\mathrm{BR}$ and HV. Similar proportions of activated $\mathrm{CD}^{+} 9^{+}$ $\mathrm{CD}^{+} \mathrm{T}$ cells were seen in BR and HV following stimulation with P.aeruginosa and H.influenzae, all being significantly higher than the unstimulated (medium) control (Fig. 5a). Co-staining of the activated $\mathrm{CD}^{+}{ }^{+} \mathrm{T}$ cells with CD69 and for IFN $\gamma$ intracellularly showed a concordance of the two forms of activation but showed that there were more $\mathrm{CD} 69^{+}$cells than $\mathrm{IFN}^{+}$cells (Additional file 1). Staining of the $\mathrm{CD} 69^{+}$stimulated cells for other potentially important markers (see Additional file 1: Figure S1), showed significant levels of staining (above isotype controls) on $\mathrm{CD} 4^{+} \mathrm{CD} 69^{+} \mathrm{T}$ cells (Fig. 5b-e), but no significant difference between BR patient and HV cells.

When the relationship between $\mathrm{T}$ cell responses (IFNY ELIspot) and lung function $\left(\mathrm{FEV}_{1} \%\right.$ predicted) was examined, a significant positive correlation (Fig. 6a), albeit weak ( $r=0.201 ; p=0.033)$, was found only with $\mathrm{T}$ cell response against H.influenzae. With removal of the outlier, significance was still retained $(r=0.186, p=0.049)$. Furthermore, a stronger (negative) correlation was observed between BSI and anti-H.influenzae $\mathrm{T}$ cell responses (Fig. 6c) $(r=-0.287 ; p=0.003)$, and again significance remained upon removal of an outlier $(r=-0.265, p=0.0035)$. Conversely, a moderate negative correlation was seen (Fig. 6b) with antibodies against H.influenzae ( $r=-0.224 ; p=0.018)$, but none with BSI (Fig. 6d). This suggests that $\mathrm{T}$ cell responses are associated with improved lung function and less severe disease, whereas higher levels of $H$. influenzae antibodies are associated with poorer lung function. Overall, no relationships were evident between the magnitudes of antibody and $\mathrm{T}$ cell responses against any of the bacteria examined. Furthermore, $\mathrm{T}$ cell and antibody responses against bacteria showed no relationships with one another (data not shown). 

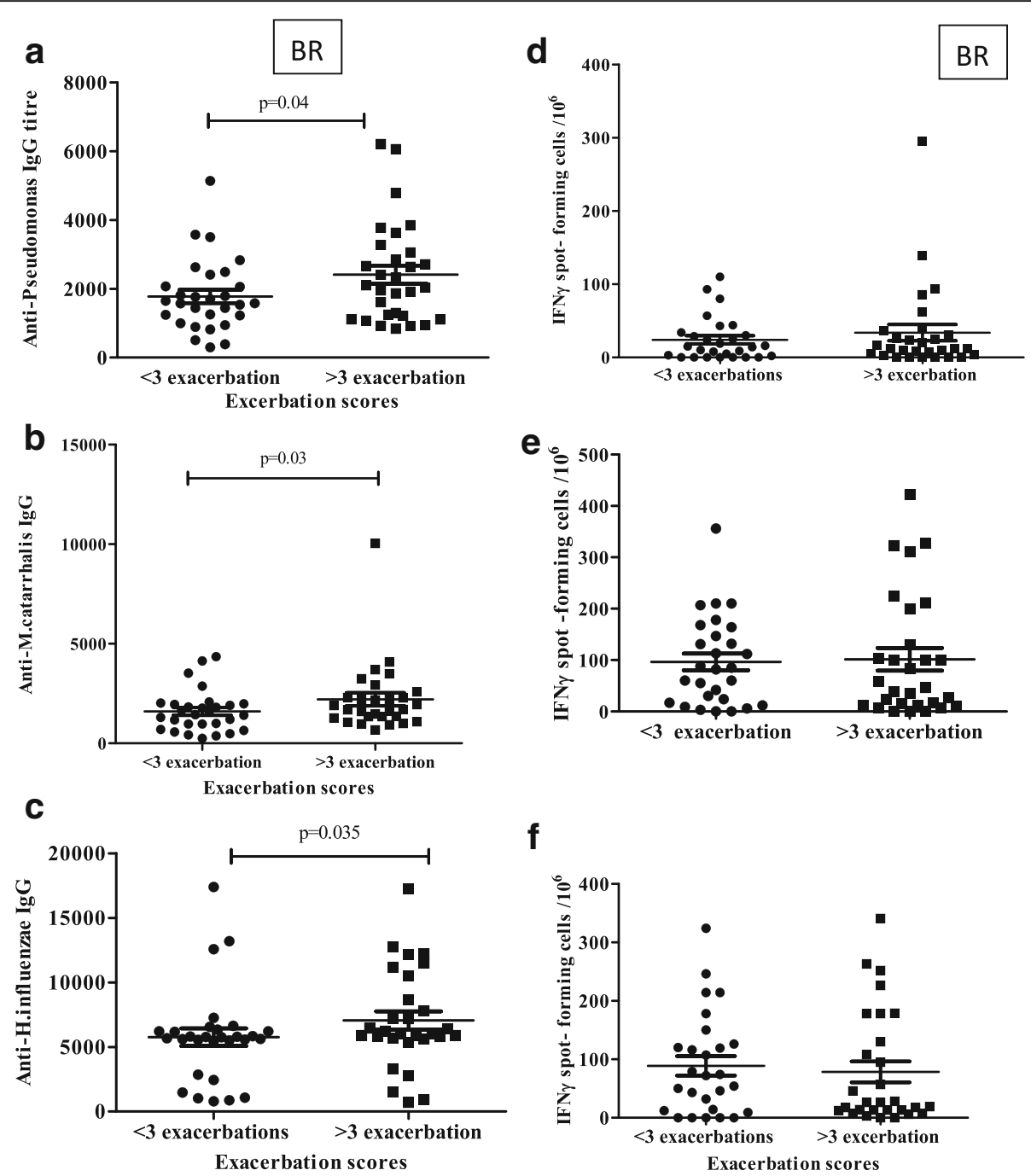

Fig. 3 Antibody and T cell responses in BR groups of different recent exacerbation history. Antibody levels against bacterial antigens were measured by ELISA to give IgG titres ( $1 /$ value) in BR groups with $<3$ compared to $>3$ exacerbations in the last 12 months against bacteria. T cell responses were measured by IFNY ELIspot and expressed as spot-forming cells per $10^{6}$ PBMC. (a, d) P.aeruginosa (b, e) M. catarrhalis (c, f) H.influenzae. Mean values + SEM are given. Mann-Whitney tests were performed

\section{Discussion}

This study began by comparing immune responses against common lung pathogens in BR, COPD and HV. The clinical categorisation of the patients followed standard processes and was in keeping with other studies in the field, as were the microbiology results obtained. One expectation was that the degree of exposure to the microbes will be proportional to the magnitude of immune response measured. This was broadly the case for antibody responses, which were higher in BR than COPD and HV, particularly against P.aeruginosa, H.influenzae and S.maltophilia, reflecting rates of positive sputum cultures in BR and COPD. Measurement of isotype components of the antibody responses against P.aeruginosa showed a high IgG1 component in BR and $\mathrm{HV}$, compared to COPD which had a higher IgM. This may suggest that COPD has reduced isotype switching, which is usually controlled by cognate $\mathrm{T}$ cell responses, through CD40:CD40L interaction and through cytokines. Reduced or altered antibody responses as we have seen here could be due to increased regulatory $\mathrm{T}$ cells, as have been demonstrated in COPD, which may depress protective immunity [29].

Having found specific antibody responses to be increased in BR, the question was whether these responses showed a direct dynamic relationship with colonization levels. Sufficient numbers for this analysis were only available in the BR group. Whilst there was a trend for increasing antibodies with colonisation for each individual pathogen, only P.aeurginosa and S.maltophilia showed significance. We categorised patients based on their exacerbation frequency $(<3, \geq 3)$ which were validated by 


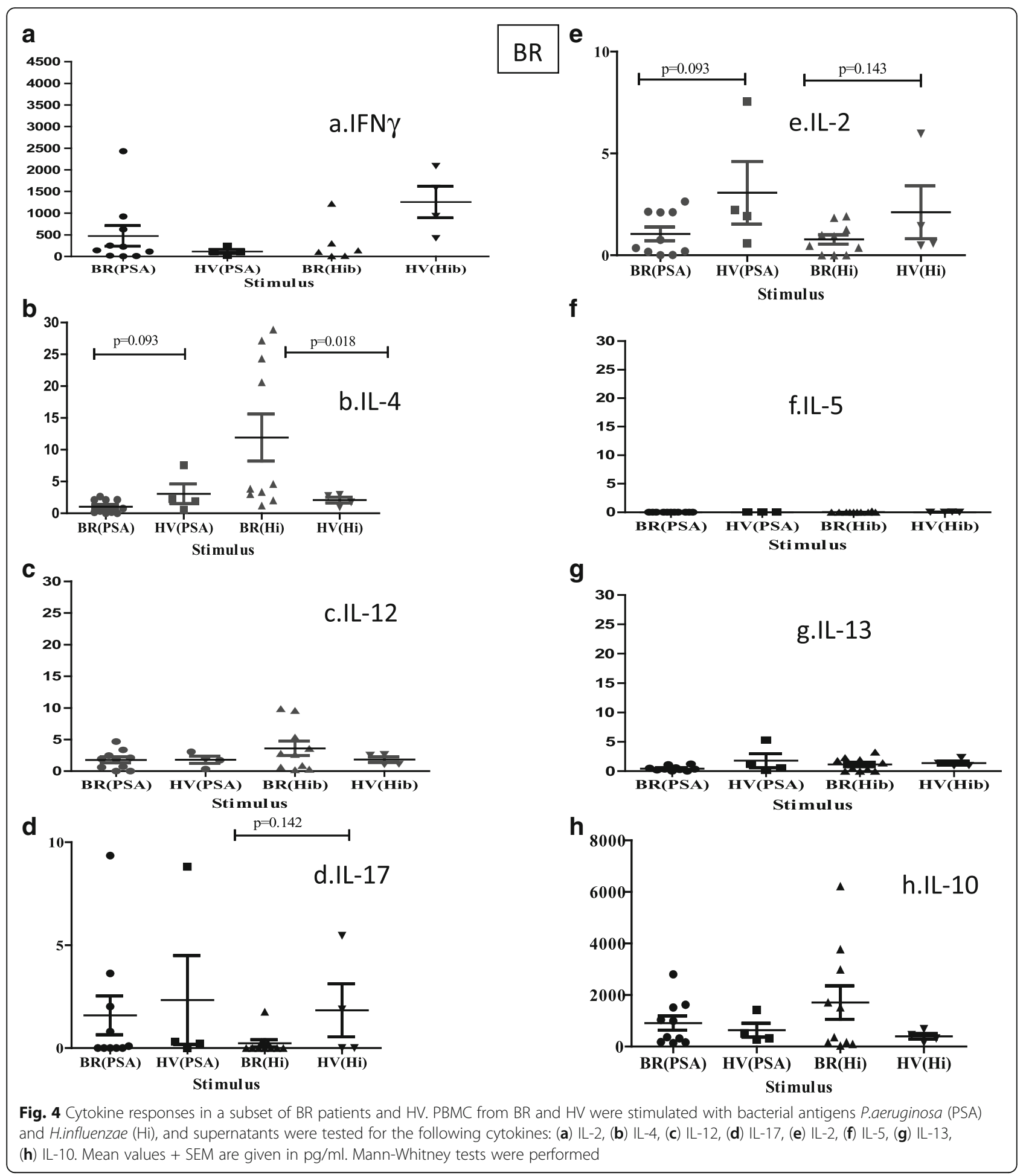

showing reducing lung function. Although significant, only modest increases in antibody against P.aeruginosa, M.catarrhalis and H.influenzae were found in BR with $\geq 3$ exacerbations compared to $<3$. Antibody response only against H.influenzae showed a negative correlation with
$\mathrm{FEV}_{1} \%$ predicted, suggesting it to be a marker of disease and exposure.

The measurement of $\mathrm{T}$ cell responses against lung pathogens may be useful for the diagnosis of latent infection, as is the case of the Quantiferon test for 


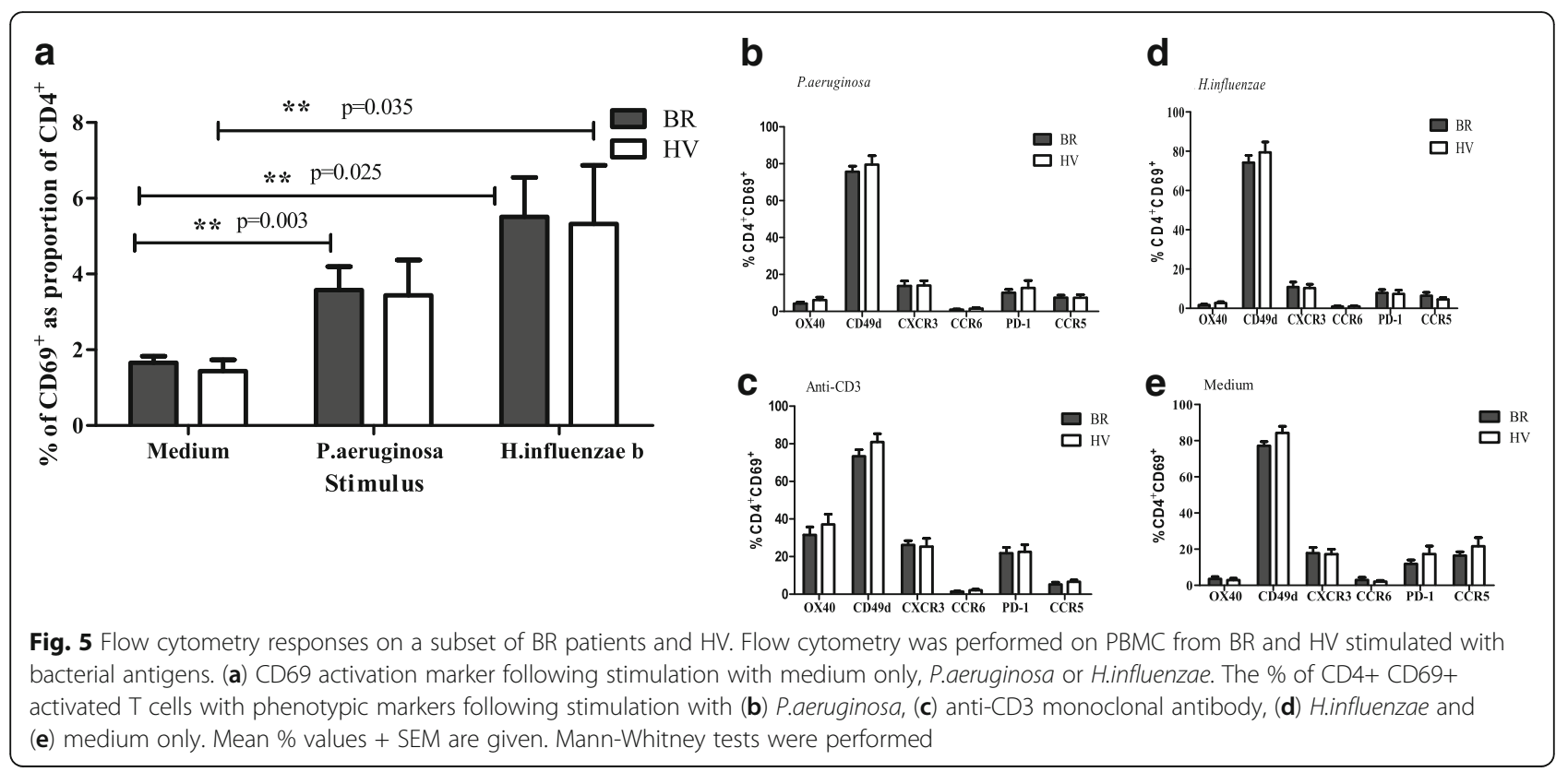

Mycobacterium tuberculosis (Mtb). In this study $\mathrm{T}$ cell responses showed an overall tendency for reduction in $\mathrm{BR}$ and COPD compared to HV, associated with colonisation status, with responses to P.aeruginosa and S.pneumoniae being significantly reduced. This suggests that increased infection and exposure may exhaust the $\mathrm{T}$ cell response.
Within the BR group $\mathrm{T}$ cell responses showed a trend for being highest in the group that had occasional infections, for all pathogens tested. The highest $\mathrm{T}$ cell responses were found for H.influenzae and M.catarrhalis which coincides with them having intracellular phases that require $\mathrm{T}$ cells for efficient immune protection or eradication. $\mathrm{T}$ cell

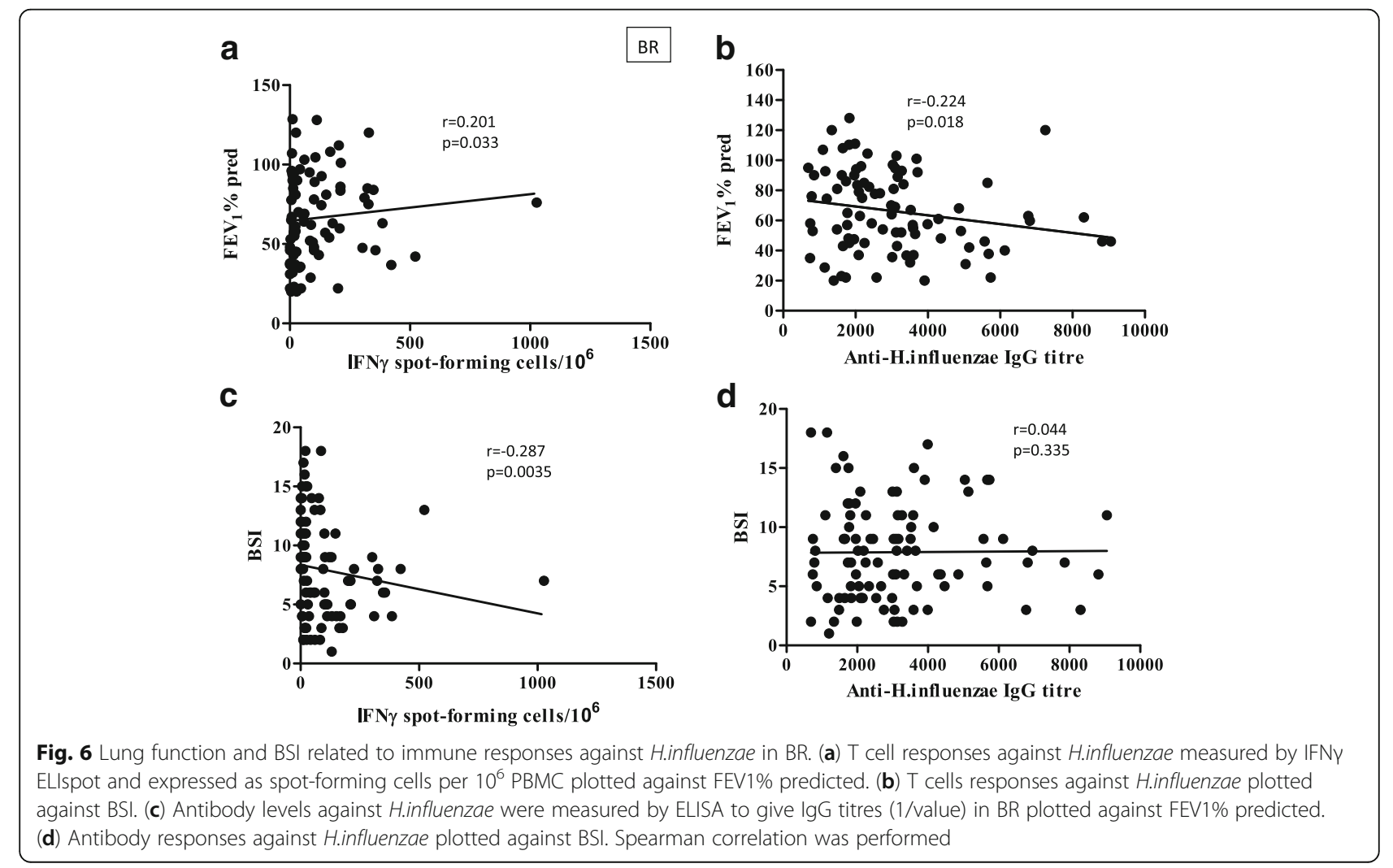


responses did not show any associations with exacerbation level. However, increased IFN $\gamma$ ELIspot $\mathrm{T}$ cell responses against H.influenzae showed significant positive association, albeit weak, with lung function $\left(\mathrm{FEV}_{1} \%\right)$ and negative association with BSI, which may suggest that $\mathrm{T}$ cells are protective against disease, in contrast to antibody responses which showed a negative correlation with $\mathrm{FEV}_{1} \%$, and may simply be associated with more infection. The next aim was to investigate further the nature of the $\mathrm{T}$ cells reactive against the two major pathogens, P.aeruginosa and H.influenzae, in a sub-group of BR patients who were good responders to the antigens and in comparison to good-responding HV. There was a tendency for IFN $\gamma$, IL-2 and IL-17 to be reduced in BR patients compared to $\mathrm{HV}$, suggesting greater antigen exposure, where memory $\mathrm{T}$ cells producing IL-2 convert to T cells secreting effector cytokines. Conversely, there was a tendency for IL-10 to be increased in BR for both antigens suggesting their conversion to a regulatory ( $\operatorname{Tr} 1)$ phenotype due to high and sustained antigen exposure at the mucosal surface. IL-4 responses showed a significant increase in $\mathrm{BR}$ against H.influenzae, similar to published work on COPD [30], but a tendency for the opposite for P.aeruginosa. This suggests a discrepancy in immune responses between BR and $\mathrm{HV}$, and against the two pathogens, reflecting the fact that T cell response against H.influenzae was protective against disease. When pathogen-reactive T cells, based on CD69 and CD4 staining, were examined for further key phenotypic markers no differences were found between BR and HV. All reactive cells had high levels of CD49d, a lung homing receptor, but low levels of inflammatory homing receptors and the marker of senescence PD-1.

The measurement of antibodies and T cells specific for P.aeruginosa and H.influenzae in patients with BR [31, $32]$ and COPD [30, 33] has previously revealed increased antibody responses associated with repeated infection, but decreased $\mathrm{T}$ cell responses, despite $\mathrm{CD} 4^{+} \mathrm{T}$ cell presence and oligoclonal TcR T cell expansion in the lungs [34, 35], suggesting immune dysregulation such as $\mathrm{T}$ cell exhaustion. Thus, while immune responses may be protective, or a marker of infection by microbes, their dysregulation may be detrimental to the patient due to reduced protection from infection or through immunopathology as suggested in cystic fibrosis [36]. Studying responses in disease states is important as this may reveal mechanisms of disease that are direct (via immunopathology) or indirect (via anti-microbial effects) that may provide therapeutic targets. Furthermore, studies of such blood-based immunodiagnostics may be useful for diagnosis and stratification of patients, and their responses to treatment [31], when microbiology or genomic analysis is not possible or reliable (young BR patients, no sputum, difficult to culture microbes, false negative). Baseline immunity related to contemporaneous microbiota may particularly be a useful way to identify a frequent exacerbator phenotype. With regard to an antibody marker of current colonization with P.aeruginosa, this data showed $92 \%$ specificity (ability to show true negatives) and $73 \%$ sensitivity (ability to show true positives) based on the HV mean $+2 \mathrm{sd}$. This is similar to previous findings [31]

The strengths of the study were the extensive nature of the immunological investigations carried out on patients, particularly those with BR, who were well characterised clinically and microbiologically. One weakness is that numbers of COPD patients producing sputum, and thus with positive cultures, was too low to allow a sufficiently powered analysis to be undertaken for COPD and so the study focussed on BR after the initial observations (Fig.1). Furthermore, it would have been useful to have longitudinal data of immune responses and microbiology, and this is the subject of a future study. Another weakness is that microbiological culture is not able to determine the complete microbial makeup in a sample if it contains fastidious unculturable bacteria. We are currently addressing this by carrying out genomic analysis of patient sputum samples as well as microbiological culture. Finally, the cytokine secretion data would have benefited from larger numbers, particularly for HV, and again this is the subject of ongoing work.

\section{Conclusion}

In conclusion, exposure to these lung pathogens generates antibody responses of magnitudes that are broadly proportional to the level of exposure and thus disease (exacerbation, reduced lung function), and may be useful markers of disease. $T$ cell responses appear to be reduced in patients with increased infection rates, and are proportional to lung function and BSI for H.influenzae, suggesting that they may be protective against such a pathogen that is partially intracellular. The $\mathrm{T}$ cell responses in patients differ little in phenotype from $\mathrm{HV}$, apart from possible subtle cytokine differences that are currently being examined further. The interaction between T cells and antibody-producing B cells, and how the two arms of the adaptive immune response interact and influence innate immunity, and ultimately impact on bacterial infection and disease, is likely to be complex and multifactorial. The data in this study suggests the use of antibodies for Pseudomonas-inducing disease diagnosis, whilst $\mathrm{T}$ cells may indicate protective immunity against Haemophilus, suggesting a possible benefit of $\mathrm{T}$ cell-inducing vaccines.

\section{Additional file}

Additional file 1: Supplement: The significance of anti-bacterial immune responses in Bronchiectasis and Chronic Obstructive Pulmonary Disease. (DOCX $235 \mathrm{~kb}$ ) 


\section{Abbreviations}

BR: Bronchiectasis; COPD: Chronic obstructive pulmonary disease; ELISA: Enzyme linked immunosorbent assay; ELIspot: Enzyme linked immunospot; FEV: Forced expiratory volume; Hi: Haemophilus influenzae; $\mathrm{HV}$ : Healthy volunteers; PSA: Pseudomonas aeruginosa

\section{Acknowledgements}

We thank John Davison for clinical assistance in this study, and Jem Palmer for help with LPS assays.

\section{Availability of data and materials}

Reasonable request for raw data and materials relating to this work can be requested from the corresponding author.

\section{Authors' contributions}

SMT, ADS and FGJ contributed to conception and design of the study. FGJ, SFH, AP, SC, JDP, SM, ADS, SMT collected and processed samples, acquired the data, analysed and interpreted the data. SMT and ADS wrote the manuscript. All authors read and critically revised the manuscript, and gave final approval for the submitted manuscript.

\section{Ethics approval and consent to participate}

Ethical approval for the project was granted by the local NHS Research Ethics Committee, the NRES Committee North East - County Durham \& Tees Valley (ref 12/NE/0248). All participants were adults who gave their informed consent.

\section{Competing interests}

ADS has received medical education grant support for a UK bronchiectasis network from GSK, Gilead, Chiesi and Forest labs. ADS's employing institution receives fees for his work as Coordinating investigator in a phase III trial in Bronchiectasis sponsored by Bayer. All other authors have no competing interests.

\section{Publisher's Note}

Springer Nature remains neutral with regard to jurisdictional claims in published maps and institutional affiliations.

\section{Author details}

${ }^{1}$ Faculty of Health \& Life Sciences, Northumbria University, Newcastle upon Tyne NE1 8ST, UK. ²Department of Microbiology, Freeman Hospital, Newcastle upon Tyne NE7 7DN, UK. ${ }^{3}$ Adult Bronchiectasis Service, Freeman Hospital, Newcastle upon Tyne NE7 7DN, UK. ${ }^{4}$ Institute of Cellular Medicine, Newcastle University, Newcastle upon Tyne NE2 4HH, UK. ${ }^{5}$ Zawia University, Zawia, Libya. ${ }^{6}$ College of Pharmacy, University of Kerbala, Kerbala, Iraq.

\section{Received: 16 February 2018 Accepted: 14 May 2018}

\section{Published online: 30 May 2018}

\section{References}

1. World Health Organisation. Global burden of diseases. 2016

2. McDonnell MJ, Aliberti S, Goeminne PC, Restrepo MI, Finch S, Pesci A, Dupont LJ, Fardon TC, Wilson R, Loebinger MR, Skrbic D, Obradovic D, De Soyza A, Ward C, Laffey JG, Rutherford RM, Chalmers JD. Comorbidities and the risk of mortality in patients with bronchiectasis: an international multicentre cohort study. Lancet Respir Med. 2016:4:969-79.

3. Cole PJ. Inflammation: a two-edged sword-the model of bronchiectasis. Eur J Respir Dis Suppl. 1986:147:6-15.

4. Angrill J, Agustí C, de Celis R, Rañó A, Gonzalez J, Solé T, Xaubet A, Rodriguez-Roisin $\mathrm{R}$, Torres A. Bacterial colonisation in patients with bronchiectasis: microbiological pattern and risk factors. Thorax. 2002;57:15-9.

5. King PT, Holdsworth SR, Freezer NJ, Villanueva E, Holmes PW. Microbiologic follow-up study in adult bronchiectasis. Respir Med. 2007;101:1633-8.

6. Tunney MM, Einarsson GG, Wei L, Drain M, Klem ER, Cardwell C, Ennis M, Boucher RC, Wolfgang MC, Elborn JS. Lung microbiota and bacterial abundance in patients with bronchiectasis when clinically stable and during exacerbation. Am J Respir Crit Care Med. 2013;187:1118-26.

7. Dickson RP, Martinez FJ, Huffnagle GB. The role of the microbiome in exacerbations of chronic lung diseases. Lancet. 2014;384:691-702.
8. Rogers GB, Zain NM, Bruce KD, Burr LD, Chen AC, Rivett DW, McGuckin MA, Serisier DJ. A novel microbiota stratification system predicts future exacerbations in bronchiectasis. Ann Am Thorac Soc. 2014;11:496-503.

9. Rogers GB, van der Gast CJ, Cuthbertson L, Thomson SK, Bruce KD, Martin ML, Serisier DJ. Clinical measures of disease in adult non-CF bronchiectasis correlate with airway microbiota composition. Thorax. 2013;68:731-7.

10. Wang Z, Singh R, Miller BE, Tal-Singer R, Van Horn S, Tomsho L, Mackay A, Allinson JP, Webb AJ, Brookes AJ, George LM, Barker B, Kolsum U, Donnelly LE, Belchamber K, Barnes PJ, Singh D, Brightling CE, Donaldson GC, Wedzicha JA, Brown JR, Sputum COPDMAP. Microbiome temporal variability and dysbiosis in chronic obstructive pulmonary disease exacerbations: an analysis of the COPDMAP study. Thorax. 2017;73:331-38.

11. McDonnell MJ, Jary HR, Perry A, MacFarlane JG, Hester KL, Small T, Molyneux C, Perry JD, Walton KE, De Soyza A. Non cystic fibrosis bronchiectasis: a longitudinal retrospective observational cohort study of Pseudomonas persistence and resistance. Respir Med. 2015;109:716-26.

12. Jones CJ, Wozniak DJ. Psl produced by mucoid Pseudomonas aeruginosa contributes to the establishment of biofilms and immune evasion. MBio. 2017;8(3)

13. Angrill J, Agustí C, De Celis R, Filella X, Rañó A, Elena M, De La Bellacasa JP, Xaubet A, Torres A. Bronchial inflammation and colonization in patients with clinically stable bronchiectasis. Am J Respir Crit Care Med. 2001;164:1628-32

14. Erb-Downward JR, Thompson DL, Han MK, Freeman CM, McCloskey L, Schmidt LA, Young VB, Toews GB, Curtis JL, Sundaram B, Martinez FJ, Huffnagle GB. Analysis of the lung microbiome in the "healthy" smoker and in COPD. PLoS One. 2011;6:e16384

15. Boyton RJ, Smith J, Jones M, Reynolds C, Ozerovitch L, Chaudhry A, Wilson R, Rose M, Altmann DM. Human leucocyte antigen class ॥ association in idiopathic bronchiectasis, a disease of chronic lung infection, implicates a role for adaptive immunity. Clin Exp Immunol. 2008 Apr;152(1):95-101.

16. Boyton RJ, Altmann DM. Bronchiectasis: current concepts in pathogenesis, immunology, and microbiology. Annu Rev Pathol. 2016:11:523-54.

17. Döring G, Meisner C, Stern M. Flagella vaccine trial study group. A doubleblind randomized placebo-controlled phase III study of a Pseudomonas aeruginosa flagella vaccine in cystic fibrosis patients. Proc Natl Acad Sci U S A. 2007;104:11020-5.

18. Bumann D, Behre C, Behre K, Herz S, Gewecke B, Gessner JE, von Specht BU, Baumann U. Systemic, nasal and oral live vaccines against Pseudomonas aeruginosa: a clinical trial of immunogenicity in lower airways of human volunteers. Vaccine. 2010;28:707-13.

19. Wu W, Huang J, Duan B, Traficante DC, Hong H, Risech M, Lory S, Priebe GP. Th17-stimulating protein vaccines confer protection against Pseudomonas aeruginosa pneumonia. Am J Respir Crit Care Med. 2012:186:420-7.

20. Murphy TF. Vaccines for Nontypeable Haemophilus influenzae: the future is now. Clin Vaccine Immunol. 2015:22:459-66.

21. Aguilar C, Malphettes $M$, Donadieu J, et al. Prevention of infections during primary immunodeficiency. Clin Infect Dis. 2014:59:1462-70.

22. Marsland BJ, Gollwitzer ES. Host-microorganism interactions in lung diseases. Nat Rev Immunol. 2014;14:827-35.

23. McAleer JP, Kolls JK. Directing traffic: IL-17 and IL-22 coordinate pulmonary immune defense. Immunol Rev. 2014;260:129-44.

24. Chalmers JD, Smith MP, McHugh BJ, Doherty C, Govan JR, Hill AT. Shortand long-term antibiotic treatment reduces airway and systemic inflammation in non-cystic fibrosis bronchiectasis. Am J Respir Crit Care Med. 2012;186:657-65.

25. Pasteur MC, Bilton D, Hill AT. British Thoracic Society non-CF bronchiectasis guideline group. British Thoracic Society guideline for non-CF bronchiectasis. Thorax. 2010;65:577.

26. Chalmers JD, Goeminne P, Aliberti S, McDonnell MJ, Lonni S, Davidson J, Poppelwell L, Salih W, Pesci A, Dupont LJ, Fardon TC, De Soyza A, Hill AT. The bronchiectasis severity index. An international derivation and validation study. Am J Respir Crit Care Med. 2014:189:576-85.

27. Walker KM, Okitsu S, Porter DW, Duncan C, Amacker M, Pluschke G, Cavanagh DR, Hill AV, Todryk SM. Antibody and T-cell responses associated with experimental human malaria infection or vaccination show limited relationships. Immunology. 2015;145:71-81.

28. Todryk SM, Walther M, Bejon P, Hutchings C, Thompson FM, Urban BC, Porter DW, Hill AV. Multiple functions of human T cells generated by experimental malaria challenge. Eur J Immunol. 2009;39:3042-51. 
29. Kalathil SG, Lugade AA, Pradhan V, Miller A, Parameswaran Gl, Sethi S, Thanavala Y. T-regulatory cells and programmed death $1+\mathrm{T}$ cells contribute to effector T-cell dysfunction in patients with chronic obstructive pulmonary disease. Am J Respir Crit Care Med. 2014:190:40-50.

30. King PT, Lim S, Pick A, Ngui J, Prodanovic Z, Downey W, Choong C, Kelman A, Baranyai E, Francis M, Moshinsky R, Bardin PG, Holmes PW, Holdsworth SR. Lung T-cell responses to nontypeable Haemophilus influenzae in patients with chronic obstructive pulmonary disease. J Allergy Clin Immunol 2013;131. 1314-21:e14.

31. Suarez-Cuartin G, Smith A, Abo-Leyah H, Rodrigo-Troyano A, Perea L, Vidal S, Plaza V, Fardon TC, Sibila O, Chalmers JD. Anti-Pseudomonas aeruginosa $\operatorname{lgG}$ antibodies and chronic airway infection in bronchiectasis. Respir Med. 2017;128:1-6.

32. Quigley KJ, Reynolds CJ, Goudet A, Raynsford EJ, Sergeant R, Quigley A, Worgall S, Bilton D, Wilson R, Loebinger MR, Maillere B, Altmann DM, Boyton RJ. Chronic infection by mucoid Pseudomonas aeruginosa associated with dysregulation in T-cell immunity to outer membrane Porin F. Am J Respir Crit Care Med. 2015;191:1250-64.

33. King PT, Ngui J, Gunawardena D, Holmes PW, Farmer MW, Holdsworth SR. Systemic humoral immunity to non-typeable Haemophilus influenzae. Clin Exp Immunol. 2008;153:376-84.

34. Sze MA, Dimitriu PA, Suzuki M, McDonough JE, Campbell JD, Brothers JF, Erb-Downward JR, Huffnagle GB, Hayashi S, Elliott WM, Cooper J, Sin DD, Lenburg ME, Spira A, Mohn WW, Hogg JC. Host response to the lung microbiome in chronic obstructive pulmonary disease. Am J Respir Crit Care Med. 2015:192:438-45.

35. Sullivan AK, Simonian PL, Falta MT, Mitchell JD, Cosgrove GP, Brown KK, Kotzin BL, Voelkel NF, Fontenot AP. Oligoclonal CD4+ T cells in the lungs of patients with severe emphysema. Am J Respir Crit Care Med. 2005;172:590-6.

36. Robinson KM, Alcorn JF. T-cell immunotherapy in cystic fibrosis: weighing the risk/reward. Am J Respir Crit Care Med. 2013;187(6):564.

\section{Ready to submit your research? Choose BMC and benefit from:}

- fast, convenient online submission

- thorough peer review by experienced researchers in your field

- rapid publication on acceptance

- support for research data, including large and complex data types

- gold Open Access which fosters wider collaboration and increased citations

- maximum visibility for your research: over $100 \mathrm{M}$ website views per year

At BMC, research is always in progress.

Learn more biomedcentral.com/submissions 